WellBeing International

WBI Studies Repository

8-1997

\title{
Life in Captivity: Its Lack of Opportunities for Variable Behaviour
}

Françoise Wemelsfelder

Scottish Agricultural College

Follow this and additional works at: https://www.wellbeingintlstudiesrepository.org/acwp_zoae

Part of the Animal Studies Commons, Behavior and Ethology Commons, and the Comparative Psychology Commons

\section{Recommended Citation}

Wemelsfelder, F. (1997). Life in captivity: its lack of opportunities for variable behaviour. Applied Animal Behaviour Science, 54(1), 67-70.

This material is brought to you for free and open access by WellBeing International. It has been accepted for inclusion by an authorized administrator of the WBI Studies Repository. For more information, please contact wbisr-info@wellbeingintl.org.

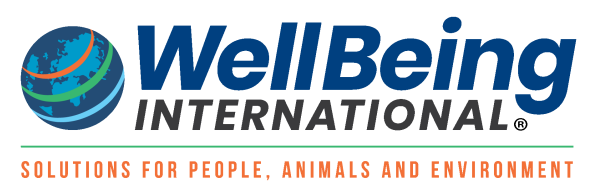




\section{Life in Captivity: Its Lack of Opportunities for Variable Behaviour}

Françoise Wemelsfelder

Scottish Agricultural College

In "Life in a variable world", Mike Appleby asserts that environmental stimulation forms a large and infinitely variable continuum. This property is reflected in the organisation of behaviour; Appleby argues that there are no distinct optimal states or 'needs' towards which an animal's behaviour is directed. animals merely respond towards the range of stimuli available to them, sometimes in adaptive, sometimes in maladaptive fashion. The distinction between natural and artificial environments, and normal and abnormal behaviour, thus loses much of its meaning. Well-being becomes a relative value, emerging out of a complex multiplicity of underlying factors affecting the animal's behaviour. This would make it impossible to predict with any amount of certainty under which circumstances well-being may or may not arise. Appleby therefore proposes that an external frame of reference is needed to establish desirable features of environmental design. He concludes that cost-benefit analysis may provide the 'optimal' logical framework for informed decision-making on problems of animal welfare.

The value of this paper is that it puts forward variability and complexity as issues which, in an animal welfare context, need in-depth consideration in their own right. The interaction of animals with their environment, the paper argues, is too multifaceted and complex to warrant a definition of welfare in terms of distinct 'needs'. Such an argument is timely, given the growing scientific interest in animal cognition and decision-making. It also may positively affect practical issues of environmental design, implying that man-made housing environments, though artificial by definition, could be made sufficiently complex to generate a satisfactory level of welfare. This may stimulate institutions which formerly felt forced to create wildlife safari parks on their premises (with all the accompanying resentment), to take a more constructive attitude in designing appropriate housing systems.

Despite my sympathy with the overall theme of the paper, however, I do not agree with the direction of its line of argument. Appleby's views on environmental variability seem to point towards the rather defeatist stance that clear-cut standards of welfare and environmental design are not possible, unless we call upon economic cost factors. I would like to question this conclusion, starting with a closer look at the definition of the concept of variability itself.

The way in which the term 'variability' is applied in the context of this paper is problematic. It is used in an extremely broad sense, to indicate that the physical world and its stimulus effects form a continuum consisting of infinitely subtle gradations. But strictly speaking, this is not to say that perceived stimulus effects are variable. The term 'variability' denotes more than the perception of a continuum from suboptimal to supernormal stimulation, it denotes the perception of 'change' and 'novelty' as effects in their own right. This may seem a minor linguistic point, but it has rather large consequences. By a priori assuming that "many or most stimuli in the environment are variable" (section 21. Appleby begs the question of whether present housing conditions are indeed sufficiently variable and complex to facilitate a satisfactory level of well-being. 
This problem comes to light in the paragraph 'Motivation for general stimuli'. Here, it is suggested that novelty and variety, like other stimulus effects, exist on a continuous scale, and can appear in supernormal form. So variety should, no more than food and shelter, be regarded as a distinct 'need'. Everything is variable, including variety. The consequence of this view is that the concept of variability loses its discriminating power. For example, Appleby proposes that both persistent foraging behaviour in pigs and hens, and the active soliciting by dogs of walks and play with humans, are a response to supernormal stimulation provided by human caretakers. Thus, these forms of behavior are put on one line with stereotyped wheel-running in rats and compulsive channel-hopping in humans. However, to assume out of hand that the enthusiastic bouncing of the dog who takes his caretaker on a walk is of the same category as the morose fixation of the couch potato with his TV set, seems to me unjustified. The former response seems voluntary, flexible and varied, while the latter appears more passive and stereotyped. The concept of variability should perhaps be used to discriminate between these different styles of behaviour, rather than to unite them into one broad continuum.

Appleby does not consider this option. The reason for this is that he regards variability and complexity, and indeed 'needs' in general, primarily as stimulus properties, as perceptive categories. Behaviour then is regarded purely in response terms, that is as a passive reaction to the environment. What the animal wants or needs is seen as external; behaviour merely serves to figure out the best way to get it. This approach is in line with that taken by psychologists who earlier this century sought to demonstrate the reward value of stimulus novelty and complexity (e.g. Dember et al., 1957; Berlyne, 1960). These scientists were in fact important fore-runners of the cognitive turn which behavioural research seems to have recently taken. However, the cognitive paradigm, in its emphasis on perception, does not sufficiently take into consideration that active behaviour may have a reward value, not just as a means towards a perceived end, but as an end in itself (Wemelsfelder, 1993a). A captive animal's 'needs' may lie as much in the 'doing' as in the 'achieving'. This would fill its time (Hughes and Duncan, 19881, meet its interest in play and exploration (Wood-Gush and Vestergaard, 1991, 19931, and prevent it from getting bored (Wemelsfelder, 1993b).

The primacy of behaviour is not just valid for captive animals; it is a general principle of organisation. Behaviour is not the result, but the source of perception; what is perceived in the external environment is dependent upon the behavioural capacities and options available. A stormy sea with high, overpowering waves may be a fantastic, enjoyable sight from a shore pier, but a life-threatening experience from an unstable ferry boat. Both situations present considerable variety to the observer, but rather differ in experience of welfare. This illustrates that it is the behavioural perspective which sets the mode in which perceptions are formed and categorised. This fundamental insight has been put forward and elaborated by Gibson, in his well-known theory of vision (Gibson, 1950, 1979). Gibson (1979) uses the term 'affordance' to indicate the behaviour-relative nature of perception. Water can be a cool bath, a life-saving drink, and a barrier to safety. Our response to water in each of these situations will be entirely different; what we perceive, in the most direct sense of the word, is not merely water, but what water affords us to do.

Thus, it is not the specific stimuli properties of an environment that count, but what they afford an animal to do. The perception of variability and complexity is not automatic, but is dependent on the animal's active engagement with the environment. By moving through the environment, by turning over stones, by looking behind barriers, by courting a mate, the variability inherent in that environment is discovered. Such interaction moreover must be voluntary. It is only when given the opportunity to move around freely, that animals can explore the different aspects of the environment. When forcibly introduced to an environment, it is more likely that their response will be one of withdrawal or escape. I suggest, then, that it is not strictly true to say that all stimulation 'is' variable. Whether or not this is the case depends upon 
the animal's behavioural perspective. In other words, the organisation of behaviour is more of a Response-Stimulus nature than of a Stimulus-Response nature (Bolles, 1972).

The implication of this for standards of animal welfare and environmental design is that these should primarily be behaviour-, not stimulus-based. Indeed, as Appleby points out, we cannot know in any absolute sense what the different aspects of the environment mean to an animal. But then, we do not need to know. All we need to do is to provide an environment which enables the animal to be functionally creative. The animal then will generally know how to use the available substrates in an adequate way, as for example the studies of Stolba and Wood-Gush (1989) on the behaviour of pigs in a semi-natural environment have shown. That animals occasionally make mistakes, as Appleby illustrates with several examples, does not take away from this principle. The norm for appropriate environmental design should thus be the animal's active role, not economic cost. A successful environment will enhance this role, as measured by parameters such as exploration, play, social interaction and general liveliness. We may not know exactly what makes such an environment a good one, but we will know that an acceptable standard of welfare has been achieved. Does such an approach imply that wildlife safari parks should be the norm? I do not think so, in that it leaves open the possibility that artificial devices may be as effective and satisfactory as purely natural features. However, experience has shown that artificial objects such as TV screens and computer games may well lose their effectiveness after the initial novelty has worn off. It is mostly natural features, or close imitations thereof, that provide the most effective source of meaningful stimulation to an animal (Hutchins et al., 1978). The challenge in environmental design, then, seems to be the creation of housing systems which facilitate and draw out the functional structure of animal behaviour in a manageable and viable way.

This should of course take into account economic interests, but I do not think such interests should play a norm-providing role within the field of animal welfare itself, as Appleby suggests. The norm in this field is the study of the animal's point of view and its interests, and the design of housing conditions which take these as their starting point. Economics form an important limiting factor in achieving this goal, and should therefore be worked with, and overcome, as much as possible. In the end, however, it is not up to scientists of animal welfare to weigh the interests of animals against those of human economics. Indeed, there can be no common currency between these interests for the sake of straightforward cost-benefit analysis, because to weigh interests is an ethical procedure, not a scientific one. Ethical decisions must be informed by knowledge of ethical principles, and must be made by representatives of the public at large. That said, however, I do agree with Appleby that in order to make effective progress in environmental design, co-operation between different interest groups is a good thing, and is more than likely to benefit animals. Such co-operation makes the weighing process a human activity rather than a scientific calculus, and asks that we examine our individual norms and beliefs. This seems appropriate, placing the scientist firmly within, not above, the public debate.

\section{References}

Berlyne, D.E., 1960. Conflict, Arousal and Curiosity. McGraw-Hill, New York.

Bolles, R.C., 1972. Reinforcement, expectancy and learning. Psychol. Rev., 79: 394-409.

Dember, W.N., Earl, R.W. and Paradise, N., 1957. Response by rats to differential stimulus complexity. J. Comp. Physiol. Psychol., SO: 514-518.

Gibson, J.J., 1950. The Perception of the Visual World. Houghton-Mifflin, Boston.

Gibson, J.J., 1979. The Ecological Approach to Visual Perception. Erlbaum, Hillsdale.

Hughes, B.O. and Duncan, I.J.H., 1988. The notion of ethological 'need', models of motivation and animal welfare. Anim. Behav., 36: 1696-1707. 
Hutchins, M., Hancocks, D. and Calip, C., 1978. Behavioural engineering in the zoo: a critique, part II. Int. Zoo News, 25: 18-23.

Stolba, A. and Wood-Gush, D.G.M., 1989. The behavior of pigs in a semi-natural environment. Anim. Prod., 48: 419-425.

Wemelsfelder, F., 1993a. Animal Boredom: towards an empirical approach of animal subjectivity. Elinkwijk, Utrccht. PhD thesis, available from the author only.

Wemelsfelder, F., 1993b. The concept of animal boredom and its relationship to stereotyped behaviour. In: A.B. Lawrence and J. Rushen (Editors), Stereotypic Behaviour: Fundamentals and Applications to Animal Welfare. CAB International, Wallingford, pp. 65-95.

Wood-Gush, D.G.M. and Vestergaard, K., 1991. The seeking of novelty and its relation to play. Anim. Behav., 42: 599-606.

Wood-Gush, D.G.M., and Vestergaard, K., 1993. Inquisitive exploration in pigs. Anim. Behav., 45: 185187. 